This is the peer reviewed version of the following article: Bonet, K. et al. Effect if acyl-acceptor stepwise addition strategy using alperujo oil as a substrate in enzymatic biodiesel synthesis in Journal of chemistry technology and biotechnology, vol. 93, issue 2 (Feb. 2018), p. 541-547.

Which has been published in final form at DOI 10.1002/jctb.5399

This article may be used for non-commercial purposes in accordance with Wiley terms and conditions for use of self-archived versions. 
1 Title: Effect of acyl-acceptor stepwise addition strategy using alperujo oil as a substrate

2 in enzymatic biodiesel synthesis.

3 Authors: Bonet-Ragel, Kírian; Canet, Albert; Benaiges, M. Dolors; Valero, Francisco.

4 Corresponding author: Valero, Francisco. Francisco.Valero@uab.cat

\section{Permanent address:}

6

\section{ABSTRACT}

8 BACKGROUND: Using renewable feedstock sources for biodiesel production seem to

9 be a promising strategy and even more when enzymatic catalysis with lipases is used.

10 However, it is well known that these enzymes could be inactivated due to reaction

11 conditions such as temperature or alcohol concentration. In this work, the effect of temperature and initial water activity $\left(\mathrm{a}_{\mathrm{w}}\right)$ value on immobilised recombinant Rhizopus oryzae lipase (rROL) were studied. Methanolysis and ethanolysis reactions using alperujo oil with three different stepwise addition strategies were employed.

RESULTS: recombinant 1,3-positional selective $\mathrm{rROL}$ covalently immobilised on polymethacrylate amino-epoxy activated support showed maximum initial reaction rate at low $a_{w}$ value $(0,093)$. It was found that $30^{\circ} \mathrm{C}$ was the optimal temperature in terms of biocatalyst's stability during transesterification reactions. Adding alcohol at once, ethanol was clearly better acyl-acceptor in terms of stability than methanol. Productivity was found to be 2-fold higher when five pulses of ethanol were used instead of methanol. 
1 CONCLUSIONS: alperujo oil has a great potential as a low cost feedstock for biodiesel

2 production through enzymatic catalysis using a nearly semi-continuous alcohol 3 addition strategy.

4

\section{KEYWORDS}

6 Rhizopus oryzae lipase, Biodiesel synthesis, Waste oil source, Water activity, Ethanolysis,

7 Methanolysis

8

\section{INTRODUCTION}

11 Since the world fossil fuel reserves are nearly running out - the total depletion is forecasted for $2050-2060^{1,2}$ - production of biodiesel has been widely implanted in order to supply this deficiency, with a worldly production of 27,06 million tonnes in 2013 and an increase of a $68 \%$ since $2008{ }^{3}$. The use of biodiesel (mono-alkyl esters of long chain fatty acids) has its own benefits, such as its ability to be directly used in automobile engines without important treatments ${ }^{4}$, it is considered safer than fuel oil because of its higher flash point and its ignition delay due to higher cetane number ${ }^{5}$. Environmentally, the key-point of using biodiesel is its potential for greenhouse gases emission reduction, concretely it was observed that on combustions of biodiesel-fossil fuel blends, the closed-carbon cycle, levels of both carbon monoxide and dioxide and smoke were reduced ${ }^{6,7}$.

Biodiesel is produced worldly using alkali-catalysed transesterification, using feedstock oils such as corn, palm, soybean and rapeseed ${ }^{4,8}$. However, since the beginning of the 90 s, several studies have been focused on biodiesel production using second generation oils because of the principal drawback of using edible oils: its high cost, which may represent around $75 \%$ of the 
1

2 available harvest land and deforestation ${ }^{1,9}$.

3

4

5

6

7 utilisation of edible oils. alcohol to oil molar ratios than the alkali ${ }^{1,12-14}$.

overall cost. Another problem associated with edible oils is its competition for food resources, In that way, second generation biodiesel, produced from such as non-edible oils, animal fats, waste cooking oil, etc., has been seen as an alternative to reduce environmental problems and

However, the main drawback of using the second generation substrates are its high concentration of free fatty acids (FFAs), making the standard alkali-catalysed transesterification impossible due to the saponification. In that way, FFA values lower than 1$3 \%$ are needed in order to carry it out correctly ${ }^{4,10}$. To overcome this problems, the first solution is the pre-treatment of the substrates to reduce FFA content and also to remove some impurities and other components ${ }^{11}$, increasing the process steps that may lead to an increase of the process cost. Acid and heterogeneous solid base catalyst transesterification have been seen also as a solution, but these strategies exhibit slower reaction rates and they require high

One of the most attractive options due to its benefits compared with chemical transesterification is by far the enzymatic catalysis using lipases (triacylglycerol acyl-hydrolase E.C.3.1.1.3). This process requires less energy consumption, is more environmental-friendly because it does not generate as much as waste than the chemical one, and the immobilization of catalyst turns its recovery much easier ${ }^{1,15}$. Other advantage of using lipases is its perfect compatibility with FFAs. It has been widely reported not only the possibility of synthesise biodiesel by the direct esterification of FFAs ${ }^{16-18}$, but also the reaction benefits when using substrates with high FFA content ${ }^{19,20}$. In this study it is assumed that the total amount of biodiesel produced (long chain alcohol esters) come from both reactions: transesterification of triacylgrlycerols and esterification of FFAs, as it is raised by other works ${ }^{19,21,22}$. The major problems present in enzymatic-catalysed transesterification, aside the high cost of the enzyme, is the inhibition of the lipase by the acyl acceptor, mainly methanol or ethanol, which 
1

2

may cause the reduction of the enzyme lifetime. Methanol has been reported to be the principal cause of enzymatic deactivation during the transesterification reaction 15,23,24. Although this major drawback, methanol is still the most used alcohol due to its availability and economic feasibility. Nevertheless, the problem of inactivation can be partially overcome by stepwise addition of the alcohol $4,20,25,26$.

By the other side, ethanol - not as harmful for the lipase as methanol - has been also used widely for biodiesel production ${ }^{27-30}$, because of some advantages such as major solubility in triacylglycerols (TAGs) ${ }^{31}$ and its low toxicity in front methanol.

Other key parameter in enzymatic reactions is the water activity $\left(a_{w}\right)$. Some studies have stated that this parameter is important in order to achieve higher yields because it is directly linked to the reaction's thermodynamics ${ }^{32,33}$ and the hydrolytic activity of some lipases ${ }^{34,35}$. In this work, lipase dependence on initial water activity and temperature has been studied, as well as the utilisation of methanol and ethanol as an acyl acceptor via different stepwiseaddition strategies. Covalently-immobilised recombinant 1,3-positional selective Rhizopus oryzae lipase ( $r R O L)$ in a free solvent media was used in order to avoid the presence of glycerol, since acyl migration occurs in a long time reaction and favoured for the presence of solvent. Several studies have stated that glycerol may cause inactivation of lipases by adsorbing on the carrier forming a hydrophilic environment ${ }^{15,36}$.

A part form biodiesel, 2-monoacylglycerol, which a product with an added-value mainly used as a emulsifier, lubricant and food surfactant ${ }^{37,38}$, is produced. While non-specific lipases are the most used for biodiesel production, the use of positional-specific such as Rhizomucor miehei lipase (RML) have shown a great results and efficiency ${ }^{39,40}$.

In the following study, raw alperujo oil was used as a substrate for biodiesel production. Alperujo is a high-FFA non-edible oil coming from the olive extraction processes. It is a low-cost material and is a by-product easily available ${ }^{41}$. As a waste oil, the content of FFA represents an important part of it, with a value of $24 \% w t ;$ but also a high content of organic matter ${ }^{20}$. 


\section{MATERIAL AND METHODS}

3

$4 \quad$ Materials

5

6 Olive waste oil (alperujo) was kindly given from Sierra Mágina olive oil extraction mill (Mancha

7 Real, Jaén, Spain). Heptane, ethanol and methanol were purchased from Panreac (Barcelona,

8 Spain). Oleic acid and standards of methyl/ethyl palmitate, methyl/ethyl stearate,

9 methyl/ethyl oleate, methyl/ethyl linoleate and methyl linolenate were obtained from Sigma-

10 Aldrich (St Louis, USA). HFA403 ReliZyme carrier was purchased from Resindion (Binasco,

11 Milano, Italy). Colorimetric kit for enzymatic assay (11821729) was obtained from Roche

12 (Mannheim, Deuschland). Salts ( $\mathrm{LiBr}, \mathrm{KOH}, \mathrm{Nal}, \mathrm{NaBr}, \mathrm{NaCl}$ and $\mathrm{K}_{2} \mathrm{SO}_{4}$ ) were purchased from

13 Sigma Aldrich.

Lipase production and immobilisation on HFA-Relizyme

Recombinant Rhizopus oryzae lipase was produced by the Bioprocess Engineering and Applied

17 Biocatalysis group from Universitat Autònoma de Barcelona (UAB). Production methods are the same referenced in previous works ${ }^{42,43}$. Purification of the protein was carried out with an ultrafiltration and diafiltration in Tris- $\mathrm{HCl}$ buffer $10 \mathrm{mM} \mathrm{ph}=7$ with a Centrasette Pall Filtron set (New York, USA) ${ }^{44}$ and then lyophilised. Support pre-treatment was carried out as referenced in a previous work ${ }^{20}$. 
1 Lipase activity was determined by Roche colorimetric kit assay, using a Cary Varian 300

2 spectrophotometer (Palo Alto, USA) at $30^{\circ} \mathrm{C}$ in $200 \mathrm{mM}$ Tris- $\mathrm{HCl}$ buffer at $\mathrm{pH}=7.25{ }^{45}$. Protein concentration was determined by the widely used Bradford method ${ }^{46}$.

FAMEs, FAEEs and oleic acid quantification

FAMEs, FAEEs and oleic acid sample concentrations were analysed in a 7890A Agilent GC

7 (Santa Clara, USA) with a capillary column $19095 \mathrm{~N}-123$ and auto-sampler ${ }^{25}$. Values of \%RSD for FAMEs and oleic acid was 3\% and 7\%, respectively.

Fatty acid methyl esters and oleic acid determination was carried out as referenced in previous works ${ }^{19,20}$. Fatty ethyl esters determination was carried out using the same method.

\section{Transesterification reaction}

All reactions were carried out in duplicate in 10-mL closed vials, using an incubator (IKA KS 400, Staufen, Deutschland) under orbital stirring at $350 \mathrm{rpm}$, at different temperatures depending on the experiment $\left(30^{\circ} \mathrm{C}, 40^{\circ} \mathrm{C}, 50^{\circ} \mathrm{C}\right)$. Free-solvent reactions with $8 \mathrm{~g}$ of alperujo oil and the total amount of biocatalyst corresponding with a 32,000 UA were employed. The total stoichiometric amounts (2:1 alcohol to oil ratio) of methanol and ethanol were added in three different ways: one single pulse at the beginning of the reaction, five pulses with the same volume and ten pulses with decreasing volumes along the time. Stability-testing reactions were carried out by leaving the biocatalyst deposited at the vial's bottom and removing the medium at the end of the reaction. Then, vials containing the biocatalyst were stored at $4^{\circ} \mathrm{C}$ until the next reaction. 
2 Saturated salts were employed in order to achieve desired initial water activities ${ }^{47}$. The salts used were: $\operatorname{LiBr}\left(\mathrm{a}_{\mathrm{w}}=0.066\right), \mathrm{KOH}\left(\mathrm{a}_{\mathrm{w}}=0.093\right), \mathrm{Nal}\left(\mathrm{a}_{\mathrm{w}}=0.397\right), \mathrm{NaBr}\left(\mathrm{a}_{\mathrm{w}}=0.560\right), \mathrm{NaCl}\left(\mathrm{a}_{\mathrm{w}}=0.755\right)$, $\mathrm{K}_{2} \mathrm{SO}_{4}\left(\mathrm{a}_{\mathrm{w}}=0.976\right)$.

All reaction components were pre-equilibrated overnight - minimum 16h- with each salthydrates in a jar with tight fitting lid ${ }^{33}$.

\section{RESULTS AND DISCUSSION}

\section{Effect of water activity and temperature}

Some studies have stated that one of the most important reaction parameter, especially related with the kinetics, is the water activity ${ }^{47}$. Eventhough the reaction media contain mainly organic solvent and/or substrates, some water is needed to keep the enzyme active. Lipolytic activity of lipases is afected by a wide range of water activity values, depending on the specie and genus ${ }^{33,48}$. Evenmore, the optimal water activity value differs significally depending on the enzyme surround and the reaction system ${ }^{15,48}$. In this work, a recombinant Rhizopus oryzae lipase was used in free-solvent medium and it is worth noting that activity water effect in these kind of reaction media is yet understudied.

Thereby, a set of methanolysis reactions were carried out with six different initial water activity values trying to cover the entire range (from 0.033 to 0.976 ). Initial reaction rate (in $\mu \mathrm{mol} \cdot \mathrm{mL}^{-1} \cdot \mathrm{min}^{-1}$ ) was calculated for each reaction adding one pulse of methanol representing a $14 \%$ of total stoichiometric volume, in order to avoid inactivation effect on biocatalyst. As it is seen in Figure 1, higher rates were reached when lower water activity values were used. 
1 Some studies have reported the same case for the same lipase ${ }^{31}$. The maximum value was

2 achieved when $\mathrm{KOH}$ salt was used in the pre-equilibrium at $\mathrm{a}_{\mathrm{w}}=0.093$ when nearly no initial water was added to the system while at higher water activity values - using $\mathrm{K}_{2} \mathrm{SO}_{4}, 0.976$ hydrolysis took place leading to longer reactions.

6 In the following experiments, pre-equilibrium of all reaction components at $a_{w}=0.093$ were

7 carried out because of this transesterification rate boost.

8 As it is known, temperature is also a key parameter in enzyme-catalysed reactions. Higher 9 temperatures induce higher reaction rates and may reduce mass transfer limitations. On the other hand, higher temperature values can inactivate enzymes. Even though recent studies had well characterised the optimal temperature for free lipase activity ${ }^{44}$, three mild temperatures were tested in order to observe which promotes better transesterification rate of immobilised lipase. Stability studies were carried out at $30^{\circ} \mathrm{C}, 40^{\circ} \mathrm{C}$ and $50^{\circ} \mathrm{C}$ adding five pulses of methanol in order to avoid alcohol inhibition. As it can be seen in Figure 2, higher biocatalyst's stability was obtained when reactions were carried out at $30^{\circ} \mathrm{C}$, with an activity loss of $62 \%$ in the fourth cycle (total time in contact with methanol of $20 \mathrm{~h}$ ). Though higher yields and faster reactions were achieved at $40^{\circ} \mathrm{C}$ and $50^{\circ} \mathrm{C}$ (data not shown), the activity loss of the biocatalyst - $90 \%$ in $17 \mathrm{~h}$ and $95 \%$ in $10 \mathrm{~h}$, respectively - was detrimental. In that way, it is preferable to maintain the enzyme activity to reuse it in further reactions. 
1 Methanol and ethanol have been the most commonly used acyl acceptors in biodiesel

2 synthesis since these compounds are easily available and not as expensive as could be alcohols

3 with longer carbon chains such as iso-propyl alcohol ${ }^{49}$ or butanol ${ }^{50,51}$. However, it has been reported that methanol is one of the most harmful alcohols and may cause lipase deactivation 4,24 , so in order to avoid this enzymatic damage that impact on the activity of the subsequent reuses, some strategies have been proposed. Adding water to the system reduces high concentrations of methanol, but it may promote the undesired hydrolysis reaction ${ }^{25,52}$. Here is presented a comparison of one the most frequently used methods, the stepwise addition of

9 the acyl acceptors.

As it is shown in Figure 3, adding large amounts of methanol at once were detrimental for the lipase's activity and only a yield of $2.84 \%$ was achieved. Another data confirming this low initial rate is the oleic acid behaviour, which is maintained constant along the reaction. Moreover, adding the same stoichiometric amount of ethanol resulted in a reaction with a $49.61 \%$ yield in 360 minutes (taking into account that the maximum yield is $66.67 \%$ due to the $s n-1,3$-positonal specificity of the lipase) with a significant decreasing of the oleic acid (demonstrating both widely known reactions: transesterification and esterification). These results confirm how harmful is methanol in free-solvent and free-water systems, resulting in a reaction environment with high methanol concentration capable to inactivate lipase.

In order to evaluate the lipase stability at these conditions, a cycle-reactions were carried out, reusing the final biocatalyst with fresh substrate. Five methanolysis and ethanolysis reactions a total of 30 hours - were performed. As it can be seen in Figure 4, a $52.4 \%$ of the initial activity was retained in the case of ethanol (values for methanol were not shown due to the low yield obtained). 
1 Figure 5 shows both methanolysis and ethanolysis reaction with the same acyl acceptor's

2 stoichiometric amount added by 5 pulses of equal volumes. In the case of methanol, due to its lower initial rate, pulses were added every 60 minutes. The final yield achieved was $48.06 \%$ in 300 minutes, a 17-fold improvement of the previous result just doing it stepwisely. In the case of ethanol, pulses were added every 40 minutes. Here, an improvement of $17 \%$ was achieved in terms of yield, obtaining a 58.16\% in just 200 minutes.

These results match with some previous studies reporting that stepwise addition of ethanol may increase both the final yield and immobilised lipase's performance in free-solvent ${ }^{53,54}$ or in solvent system compared with the same strategy using methanol ${ }^{55}$.

In terms of stability (Figure 6), during 5 cycles of methanolysis reaction, ROL lipase lost nearly the whole capacity of synthesising biodiesel, reducing the initial activity up to $97.3 \%$. It is clear that performing a fifth cycle was detrimental for the lipase's activity, since a $40.26 \%$ of initial activity remained after the fourth cycle ( 20 hours). In the case of ethanol, along the same 20 hours ( 6 cycles), more than $90 \%$ of lipase activity was retained. Thus, adding the acyl acceptor stepwisely, not only induces the obtaining of higher yield but also reduces damage on the lipase, retaining more activity at the end of the cycles. Even so, harmful effects of methanol are present.

Next experiments were carried out adding ten pulses of acyl acceptor with decreasing volumes and increasing the addition frequency along the time. This strategy was chosen in order to emulate the yield evolution in the 5-pulse reactions, trying to add alcohol as the reaction needed it. Thus, methanol or ethanol accumulation in the system was reduced and yield and stability should be enhanced.

For the case of methanolysis reaction, shown in Figure 7, a final yield of 57.16\% was achieved (an increasing of up to $19 \%$ ) in 360 minutes. In the case of ethanolysis, a $60.25 \%$ of yield was achieved (which represents $91.28 \%$ of the theorical maximum yield) in 260 minutes. 
1

2 similar for both alcohols, when ten pulses were added - in the case of methanolysis - the

In contrast to 5-pulse reactions, where the decrease of total amount of free oleic acid was disappearing of free oleic acid total amount was faster than in ethanolysis. It seems than methanol may be a better substrate for FFA esterification than ethanol, but inactivation caused by its high concentration in the 5-pulse reactions, may produce damage on the enzyme leading it to reduce the esterification rate.

When a mass balance of total FAMEs and FFAs was made in the cases of 5-pulse and 10-pulse addition, it could be seen that the sum of both the free FFAs still present in the reaction medium and produced FAMEs resulted in a value close to the maximum theoretical FAME yield, stating that nearly all the triglycerides present in the substrate were converted to biodiesel while the rest where in form of FFAs.

In terms of stability, shown in Figure 8 , the differences seen in previous experiments get narrower. After 30 hours of reaction ( 5 cycles), the activity of the ROL lipase in presence of methanol was decreased only in a $12.31 \%$. It was a notable improvement compared with the 5-pulse methanolysis, which lost a $60 \%$ of the initial activity just in 20 hours. On the other side, an $88.11 \%$ of activity was retained in 7 cycles when ethanol was used, which corresponds to a 30.3 hours of reaction.

Table 1 shows the obtained productivity for each reaction. Methanolysis reactions' productivity were 1.83 -fold lower than ethanolysis when 5-pulse reactions were employed, and 1.45 -fold lower than ethanolysis when 10-pulse were carried out. Comparing both methanolysis reactions, the final productivity did not increase although methanol was added in lower volumes in order to avoid the lipase inactivation. By the other hand, a decreasing of a $22.6 \%$ of the final productivity were obtained when ethanol was added using the 10-pulse stepwise addition, due to the fact that times between pulses in this case were overestimated, reducing productivity. 
1 A fact that can be drawn from this is that, as the total amount of acyl acceptors is divided the

2 differences of the harmful effect between them are minor, due to the capability of the lipase

3 to handle the volume added. This automatically ensures in applying a semi-continuous or fed-

4 batch system in order to add the chosen acyl acceptor. For the case of ethanol, this statement

5 is not as clear as in the case of methanol, due to the higher times employed in 10-pulse

6 reactions which reduce productivity achieved since no substantial yield enhancement is

7 observed.

8

\section{CONCLUSIONS}

10 Recombiant Rhizopus oryzae lipase can be used as a biocatalyst in the biodiesel synthesis

11 reaction using alperujo oil and methanol carried out at $30^{\circ} \mathrm{C}$, giving better results in terms of 12 enzymatic stability than higher temperatures. Previous pre-equilibration steps of enzyme were 13 performed in order to obtain a fixed initial water activity, determining that $a_{w}$ of 0.093 is the 14 optimal to set the faster initial rate.

Methanol and ethanol as acyl acceptors were compared. Ethanolysis initial reaction rate was higher than when methanol was used as acyl-acceptor. Adding all alcohol at once, ethanol

17 gave better results in terms of final yield and enzymatic stability, while as long as the stepwise additions were incremented, the difference between the two acyl acceptors became closer. When ten pulses were added, the ethanolysis reaction gave faster initial rate than methanolysis one, but in contrast, the lipase activity remained nearly the same in both reactions. The time of stepwise addition should be optimized for each acyl-acceptor in a semi-continuous or fed-batch alcohol addition strategy in order to get the minimum inactivation of the biocatalyst. 


\section{ACKNOWLEDGEMENTS}

3 This work has been supported by the project CTQ2013-42391-R (MINECO/FEDER, UE) of the

4 Spanish Ministry of Economy and Competitively. The group is member of 2014-SGR-452 and 5 the Reference Network in Biotechnology (XRB, Generalitat de Catalunya).

6 
21 Atabani AE, Silitonga AS, Badruddin IA, Mahlia TMI, Masjuki HH, Mekhilef S. A 3 comprehensive review on biodiesel as an alternative energy resource and its characteristics. Renew Sustain Energy Rev. 16(4):2070-93 (2012) 10.1016/j.rser.2012.01.003.

62 Szulczyk KR, McCarl BA. Market penetration of biodiesel. Renew Sustain Energy Rev. 7 14(8):2426-33 (2010) 10.1016/j.rser.2010.05.008.

83 Infinita Renovables. Biodiesel Report 2014. (2015).

Robles-Medina A, González-Moreno P, Esteban-Cerdán L, Molina-Grima E. Biocatalysis: towards ever greener biodiesel production. Biotechnol Adv. 27(4):398-408 (2009) 10.1016/j.biotechadv.2008.10.008.

Lin C-Y, Li R-J. Fuel properties of biodiesel produced from the crude fish oil from the soapstock of marine fish. Fuel Process Technol. 90(1):130-6 (2009) 10.1016/j.fuproc.2008.08.002.

Janaun J, Ellis N. Perspectives on biodiesel as a sustainable fuel. Renew Sustain Energy Rev. 14(4):1312-20 (2010) 10.1016/j.rser.2009.12.011.

Chattopadhyay S, Sen R. Fuel properties, engine performance and environmental benefits of biodiesel produced by a green process. Appl Energy. 105:319-26 (2013) 10.1016/j.apenergy.2013.01.003.

8

Calero J, Luna D, Sancho ED, Luna C, Bautista FM, Romero AA, et al. An overview on glycerol-free processes for the production of renewable liquid biofuels, applicable in diesel engines. Renew Sustain Energy Rev. 42:1437-52 (2015) 10.1016/j.rser.2014.11.007.

9 Aarthy M, Saravanan P, Gowthaman MK, Rose C, Kamini NR. Enzymatic transesterification for production of biodiesel using yeast lipases: An overview. Chem Eng Res Des. 92(8):1591-601 (2014) 10.1016/j.cherd.2014.04.008.

Meher L, Vidyasagar D, Naik S. Technical aspects of biodiesel production by transesterification-a review. Renew Sustain Energy Rev. 10(3):248-68 (2006) 10.1016/j.rser.2004.09.002.

11 Berchmans HJ, Hirata S. Biodiesel production from crude Jatropha curcas L. seed oil with a high content of free fatty acids. Bioresour Technol. 99(6):1716-21 (2008) 10.1016/j.biortech.2007.03.051.

12 Thiruvengadaravi KV, Nandagopal J, Baskaralingam P, Sathya Selva Bala V, Sivanesan S. Acid-catalyzed esterification of karanja (Pongamia pinnata) oil with high free fatty acids for biodiesel production. Fuel. 98:1-4 (2012) 10.1016/j.fuel.2012.02.047.

13 Balat M, Balat H. Progress in biodiesel processing. Appl Energy. 87(6):1815-35 (2010) 10.1016/j.apenergy.2010.01.012.

14 Ye B, Qiu F, Sun C, Li Y, Yang D. Biodiesel production from soybean oil using heterogeneous solid base catalyst. J Chem Technol Biotechnol. 89(7):988-97 (2014) 10.1002/jctb.4190.

15 Fjerbaek L, Christensen K V, Norddahl B. A review of the current state of biodiesel production using enzymatic transesterification. Biotechnol Bioeng. 102(5):1298-315 (2009) 10.1002/bit.22256. 
Raita M, Laothanachareon T, Champreda V, Laosiripojana N. Biocatalytic esterification of palm oil fatty acids for biodiesel production using glycine-based cross-linked protein coated microcrystalline lipase. J Mol Catal B Enzym. 73(1):74-9 (2011) 10.1016/j.molcatb.2011.07.020.

17 Nie K, Wang M, Zhang X, Hu W, Liu L, Wang F, et al. Additives improve the enzymatic synthesis of biodiesel from waste oil in a solvent free system. Fuel. 146:13-9 (2015) 10.1016/j.fuel.2014.12.076.

Rodrigues J, Canet A, Rivera I, Osório NM, Sandoval G, Valero F, et al. Biodiesel production from crude Jatropha oil catalyzed by non-commercial immobilized heterologous Rhizopus oryzae and Carica papaya lipases. Bioresour Technol. 213:88-95 (2016) 10.1016/j.biortech.2016.03.011.

Canet A, Bonet-Ragel K, Benaiges MD, Valero F. Lipase-catalysed transesterification: Viewpoint of the mechanism and influence of free fatty acids. Biomass and Bioenergy. 85:94-9 (2016) 10.1016/j.biombioe.2015.11.021.

Bonet-Ragel K, Canet A, Benaiges MD, Valero F. Synthesis of biodiesel from high FFA alperujo oil catalysed by immobilised lipase. Fuel. 161:12-7 (2015) 10.1016/j.fuel.2015.08.032.

21 Al-Zuhair S. Production of Biodiesel by Lipase - Catalyzed Transesterification of Vegetable Oils : A Kinetics Study. Biotechnol Prog. 21(5):1442-8 (2005) 10.1021/bp050195k.

22 Watanabe $Y$, Shimada $Y$, Sugihara A, Tominaga Y. Conversion of degummed soybean oil to biodiesel fuel with immobilized Candida antarctica lipase. J Mol Catal B Enzym. 17(3):151-5 (2002) 10.1016/S1381-1177(02)00022-X.

23 Kulschewski T, Sasso F, Secundo F, Lotti M, Pleiss J. Molecular mechanism of deactivation of C. antarctica lipase B by methanol. J Biotechnol. 168(4):462-9 (2013) 10.1016/j.jbiotec.2013.10.012.

24 Lotti M, Pleiss J, Valero F, Ferrer P. Effects of methanol on lipases: Molecular, kinetic and process issues in the production of biodiesel. Biotechnol J. 10(1):22-30 (2015) 10.1002/biot.201400158.

25 Canet A, Dolors Benaiges M, Valero F. Biodiesel Synthesis in a Solvent-Free System by Recombinant Rhizopus oryzae Lipase. Study of the Catalytic Reaction Progress. J Am Oil Chem Soc. 91(9):1499-506 (2014) 10.1007/s11746-014-2498-y.

26 Aguieiras ECG, Cavalcanti-Oliveira ED, Freire DMG. Current status and new developments of biodiesel production using fungal lipases. Fuel. 159:52-67 (2015) 10.1016/j.fuel.2015.06.064.

27 Huang J, Xia J, Jiang W, Li Y, Li J. Biodiesel production from microalgae oil catalyzed by a recombinant lipase. Bioresour Technol. 180:47-53 (2015) 10.1016/j.biortech.2014.12.072.

28 Carvalho AKF, Faria ELP, Rivaldi JD, Andrade GSS, Oliveira PC d., Castro HF de. Performance of whole-cells lipase derived from Mucor circinelloides as a catalyst in the ethanolysis of non-edible vegetable oils under batch and continuous run conditions. Ind Crops Prod. 67:287-94 (2015) 10.1016/j.indcrop.2015.01.035.

29 Koda R, Numata T, Hama S, Tamalampudi S, Nakashima K, Tanaka T, et al. Ethanolysis of rapeseed oil to produce biodiesel fuel catalyzed by Fusarium heterosporum lipase- 
expressing fungus immobilized whole-cell biocatalysts. J Mol Catal B Enzym. 66(1):1014 (2010) 10.1016/j.molcatb.2010.04.001.

30 Ma L, Zhou L, Jiang Y, He Y, Wang L, Gao J. Lipase based static emulsions as efficient biocatalysts for biodiesel production. J Chem Technol Biotechnol. 92(6):1248-55 (2017) 10.1002/jctb.5118.

31 J. M. Encinar *, J. F. González, J. J. Rodríguez and, Tejedor A. Biodiesel Fuels from Vegetable Oils: Transesterification of Cynara cardunculus L. Oils with Ethanol. (2002).

32 Sjursnes B, Kvittingen L, Anthonsen T, Halling P. Biocatalysis in Non-Conventional Media [Internet]. Progress in Biotechnology. Elsevier; 451-457 p. (1992) 10.1016/B978-0-44489046-7.50067-9.

33 Ma L, Persson M, Adlercreutz P. Water activity dependence of lipase catalysis in organic media explains successful transesterification reactions. Enzyme Microb Technol. 31(7):1024-9 (2002) 10.1016/S0141-0229(02)00231-4.

34 Bajaj A, Lohan P, Jha PN, Mehrotra R. Biodiesel production through lipase catalyzed transesterification: An overview. J Mol Catal B Enzym. 62(1):9-14 (2010) 10.1016/j.molcatb.2009.09.018.

35 Chamouleau F, Coulon D, Girardin M, Ghoul M. Influence of water activity and water content on sugar esters lipase-catalyzed synthesis in organic media. J Mol Catal B Enzym. 11(4-6):949-54 (2001) 10.1016/S1381-1177(00)00166-1.

36 S, Hama, Yoshida A, Tamadani N, Noda H KA. Enzymatic production of biodiesel from waste cooking oil in a packed-bed reactor: An engineering approach to separation of hydrophilic impurities. Bioresour Technol. 135:417-21 (2013) 10.1016/j.biortech.2012.06.059.

37 Nieves Sánchez, Mercedes Martínez and, Aracil* J. Selective Esterification of Glycerine to 1-Glycerol Monooleate. 1. Kinetic Modeling. (1997) 10.1021/IE9603124.

38 Bellot JC, Choisnard L, Castillo E, Marty A. Combining solvent engineering and thermodynamic modeling to enhance selectivity during monoglyceride synthesis by lipase-catalyzed esterification. Enzyme Microb Technol. 28(4):362-9 (2001) 10.1016/S0141-0229(00)00326-4.

39 Kaieda M, Samukawa T, Matsumoto T, Ban K, Kondo A, Shimada Y, et al. Biodiesel fuel production from plant oil catalyzed by Rhizopus oryzae lipase in a water-containing system without an organic solvent. J Biosci Bioeng. 88(6):627-31 (1999) 10.1016/S1389-1723(00)87091-7.

40 Calero J, Verdugo C, Luna D, Sancho ED, Luna C, Posadillo A, et al. Selective ethanolysis of sunflower oil with Lipozyme RM IM, an immobilized Rhizomucor miehei lipase, to obtain a biodiesel-like biofuel, which avoids glycerol production through the monoglyceride formation. N Biotechnol. 31(6):596-601 (2014) 10.1016/j.nbt.2014.02.008.

41 Lama-Muñoz A, Álvarez-Mateos P, Rodríguez-Gutiérrez G, Durán-Barrantes MM, Fernández-Bolaños J. Biodiesel production from olive-pomace oil of steam-treated alperujo. Biomass and Bioenergy. 67:443-50 (2014) 10.1016/j.biombioe.2014.05.023.

42 Arnau C, Ramon R, Casas C, Valero F. Optimization of the heterologous production of a Rhizopus oryzae lipase in Pichia pastoris system using mixed substrates on controlled fed-batch bioprocess. Enzyme Microb Technol. 46(6):494-500 (2010) 
10.1016/j.enzmictec.2010.01.005.

Barrigón JM, Montesinos JL, Valero F. Searching the best operational strategies for Rhizopus oryzae lipase production in Pichia pastoris Mut+ phenotype: Methanol limited or methanol non-limited fed-batch cultures? Biochem Eng J. 75:47-54 (2013) 10.1016/j.bej.2013.03.018.

44 Guillén M, Benaiges MD, Valero F. Comparison of the biochemical properties of a recombinant lipase extract from Rhizopus oryzae expressed in Pichia pastoris with a native extract. Biochem Eng J. 54(2):117-23 (2011) 10.1016/j.bej.2011.02.008.

45 Resina D, Serrano A, Valero F, Ferrer P. Expression of a Rhizopus oryzae lipase in Pichia pastoris under control of the nitrogen source-regulated formaldehyde dehydrogenase promoter. J Biotechnol. 109(1-2):103-13 (2004) 10.1016/j.jbiotec.2003.10.029.

46 Bradford MM. A rapid and sensitive method for the quantitation of microgram quantities of protein utilizing the principle of protein-dye binding. Anal Biochem. 72:248-54 (1976).

47 Halling PJ. Salt hydrates for water activity control with biocatalysts in organic media. Biotechnol Tech. 6(3):271-6 (1992) 10.1007/BF02439357.

48 Chowdary G., Prapulla S. The influence of water activity on the lipase catalyzed synthesis of butyl butyrate by transesterification. Process Biochem. 38(3):393-7 (2002) 10.1016/S0032-9592(02)00096-1.

49 Iso M, Chen B, Eguchi M, Kudo T, Shrestha S. Production of biodiesel fuel from triglycerides and alcohol using immobilized lipase. J Mol Catal B Enzym. 16(1):53-8 (2001) 10.1016/S1381-1177(01)00045-5.

50 Salis A, Pinna M, Monduzzi M, Solinas V. Biodiesel production from triolein and short chain alcohols through biocatalysis. J Biotechnol. 119(3):291-9 (2005) 10.1016/j.jbiotec.2005.04.009.

51 Moreno-Pirajàn JC, Giraldo L. Study of immobilized candida rugosa lipase for biodiesel fuel production from palm oil by flow microcalorimetry. Arab J Chem. 4(1):55-62 (2011) 10.1016/j.arabjc.2010.06.019.

52 Hama S, Tamalampudi S, Suzuki Y, Yoshida A, Fukuda H, Kondo A. Preparation and comparative characterization of immobilized Aspergillus oryzae expressing Fusarium heterosporum lipase for enzymatic biodiesel production. Appl Microbiol Biotechnol. 81(4):637-45 (2008) 10.1007/s00253-008-1689-6.

53 Watanabe Y, Shimada Y, Sugihara A, Tominaga Y. Stepwise ethanolysis of tuna oil using immobilized Candida antarctica lipase. J Biosci Bioeng. 88(6):622-6 (1999) 10.1016/S1389-1723(00)87090-5.

54 Noureddini H, Gao X, Philkana RS. Immobilized Pseudornonas cepacia lipase for biodiesel fuel production from soybean oil. (2004).

55 Raita M, Champreda V, Laosiripojana N. Biocatalytic ethanolysis of palm oil for biodiesel production using microcrystalline lipase in tert-butanol system. Process Biochem. 45(6):829-34 (2010) 10.1016/j.procbio.2010.02.002. 


\section{FIGURE CAPTIONS}

Figure 1. Initial reaction rate profile of R. oryzae as a function of water activity at $30^{\circ} \mathrm{C}$ using alperujo as a substrate.

Figure 2. Relative yield (considering first reaction yield as $100 \%$ ) of 5-pulse methanolysis reactions at three different temperatures $\left(\mathrm{A}, 30^{\circ} \mathrm{C} ; \mathrm{B}, 40^{\circ} \mathrm{C} ; \mathrm{C}, 50^{\circ} \mathrm{C}\right)$ on the biocatalyst's activity.

Figure 3. Time evolution of FAMEs, FAEEs yield and oleic acid of 1-pulse transesterification reaction using methanol and ethanol (reaction conditions: $8 \mathrm{~g}$ of alperujo oil, 1:2 alcohol to oil molar, $30^{\circ} \mathrm{C}$ and $\left.350 \mathrm{rpm}\right)$.

Figure 4. Relative yield (considering first reaction yield as 100\%) of 1-pulse ethanolysis reactions. Methanolysis reaction is not shown due to the low yield achieved.

Figure 5. Time evolution of FAMEs, FAEEs yield and oleic acid of 5-pulse transesterification reaction using methanol and ethanol. First five points correspond to five pulses (reaction conditions: $8 \mathrm{~g}$ of alperujo oil, $1: 2$ alcohol to oil molar, $30^{\circ} \mathrm{C}$ and $350 \mathrm{rpm}$ ).

Figure 6. Relative yield (considering first reaction yield as 100\%) of 5-pulse methanolysis and ethanolysis reactions.

Figure 7. Time evolution of FAMEs, FAEEs yield and oleic acid of 10-pulse transesterification reaction using methanol and ethanol. The first 10 points correspond to the 10 pulses (reaction conditions: $8 \mathrm{~g}$ of alperujo oil, $1: 2$ alcohol to oil molar, $30^{\circ} \mathrm{C}$ and $350 \mathrm{rpm}$ ).

Figure 8. Relative yield (considering first reaction yield as $100 \%$ ) of 10 -pulse methanolysis and ethanolysis reactions. 


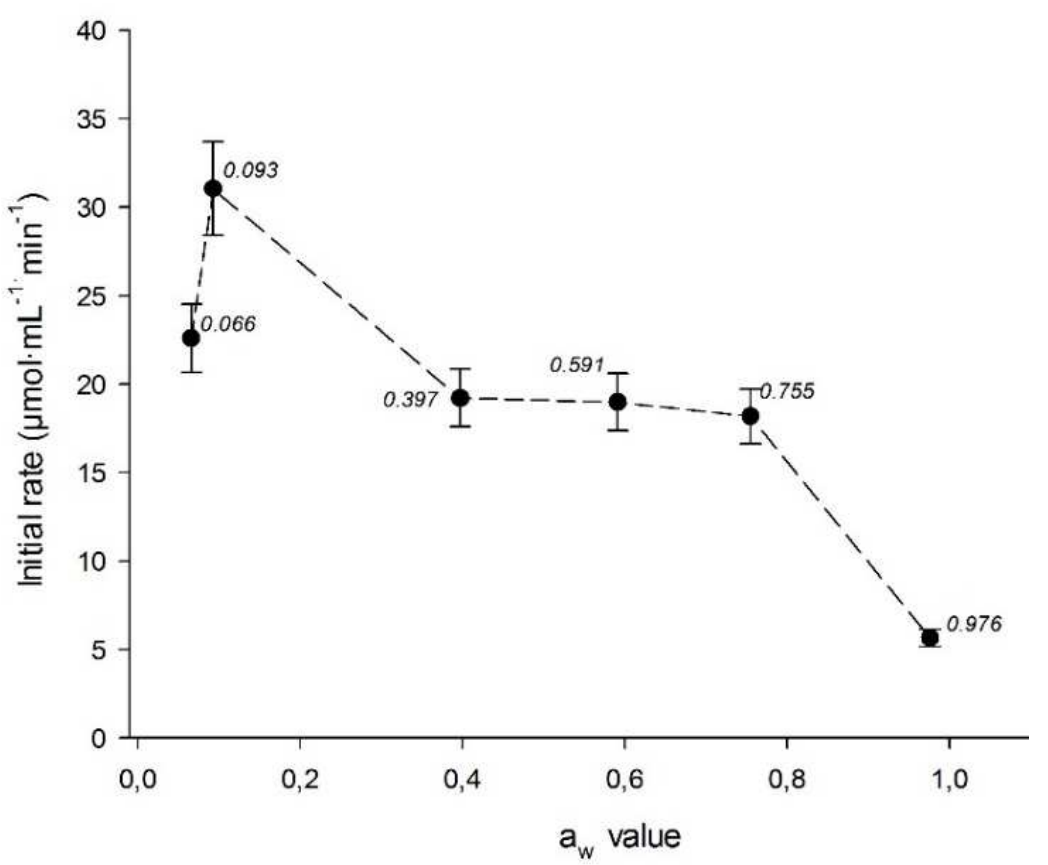

1

2 Figure 1. Initial reaction rate profile of $\mathrm{R}$. oryzae as a function of water activity at $30^{\circ} \mathrm{C}$ using 3 alperujo as a substrate.

4

5

6

7 

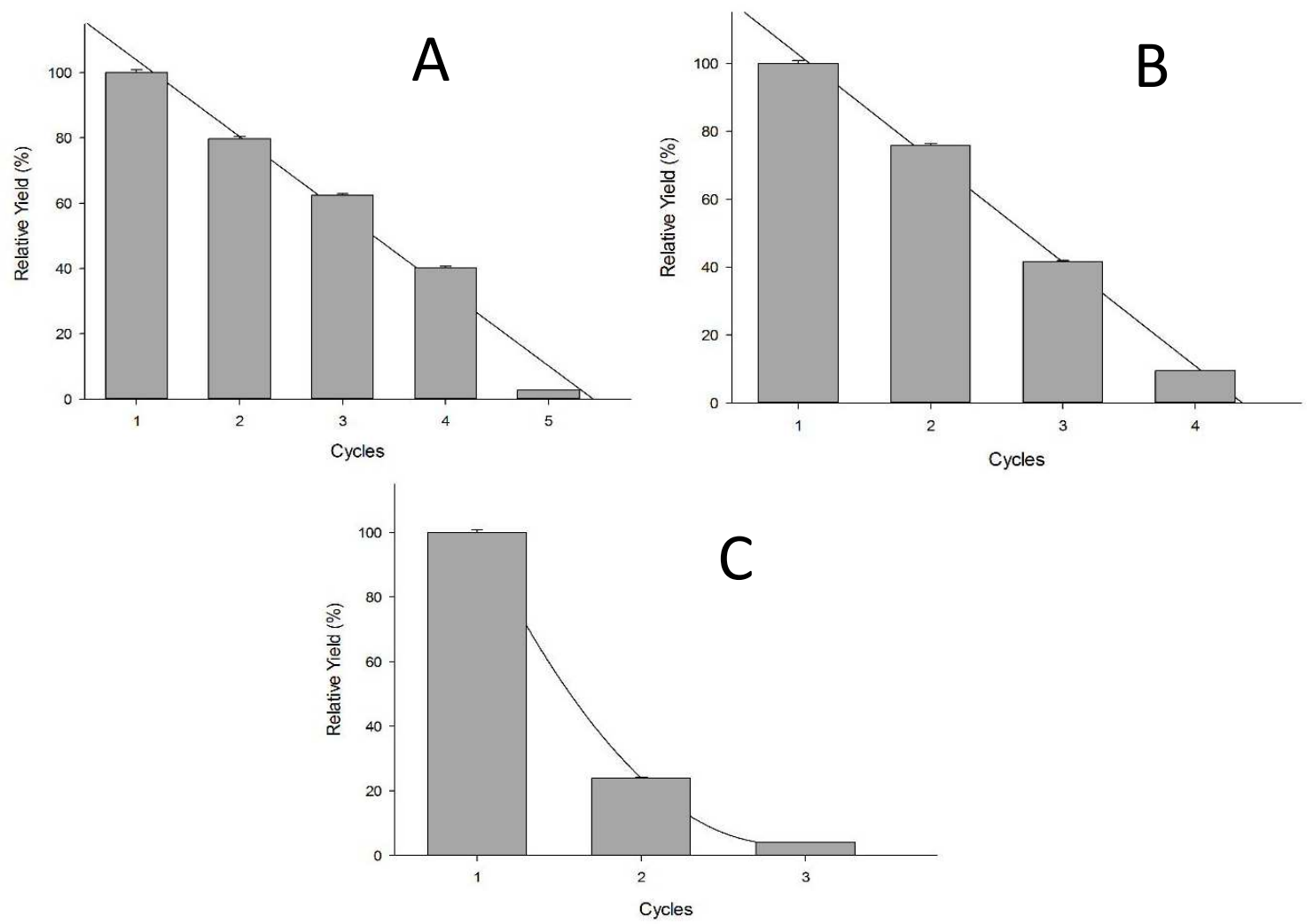

1

2 Figure 2. Relative yield (considering first reaction yield as $100 \%$ ) of 5-pulse methanolysis 3 reactions at three different temperatures $\left(\mathrm{A}, 30^{\circ} \mathrm{C} ; \mathrm{B}, 40^{\circ} \mathrm{C} ; \mathrm{C}, 50^{\circ} \mathrm{C}\right)$ on the biocatalyst's 4 activity. 


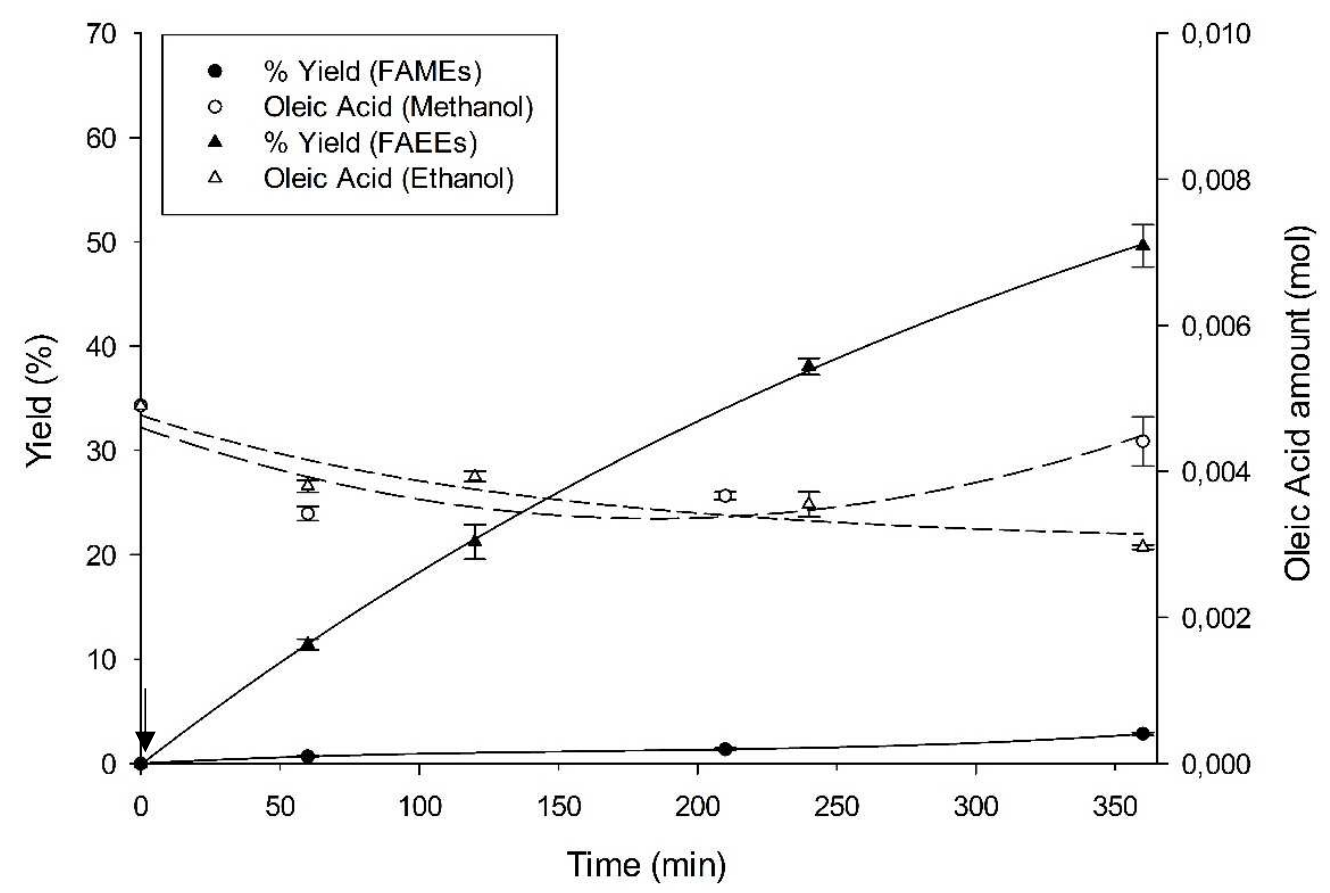

2

3

4 Figure 3. Time evolution of FAMEs, FAEEs yield and oleic acid of 1-pulse transesterification 5 reaction using methanol and ethanol (reaction conditions: $8 \mathrm{~g}$ of alperujo oil, 1:2 alcohol to oil 6 molar, $30^{\circ} \mathrm{C}$ and $\left.350 \mathrm{rpm}\right)$. 


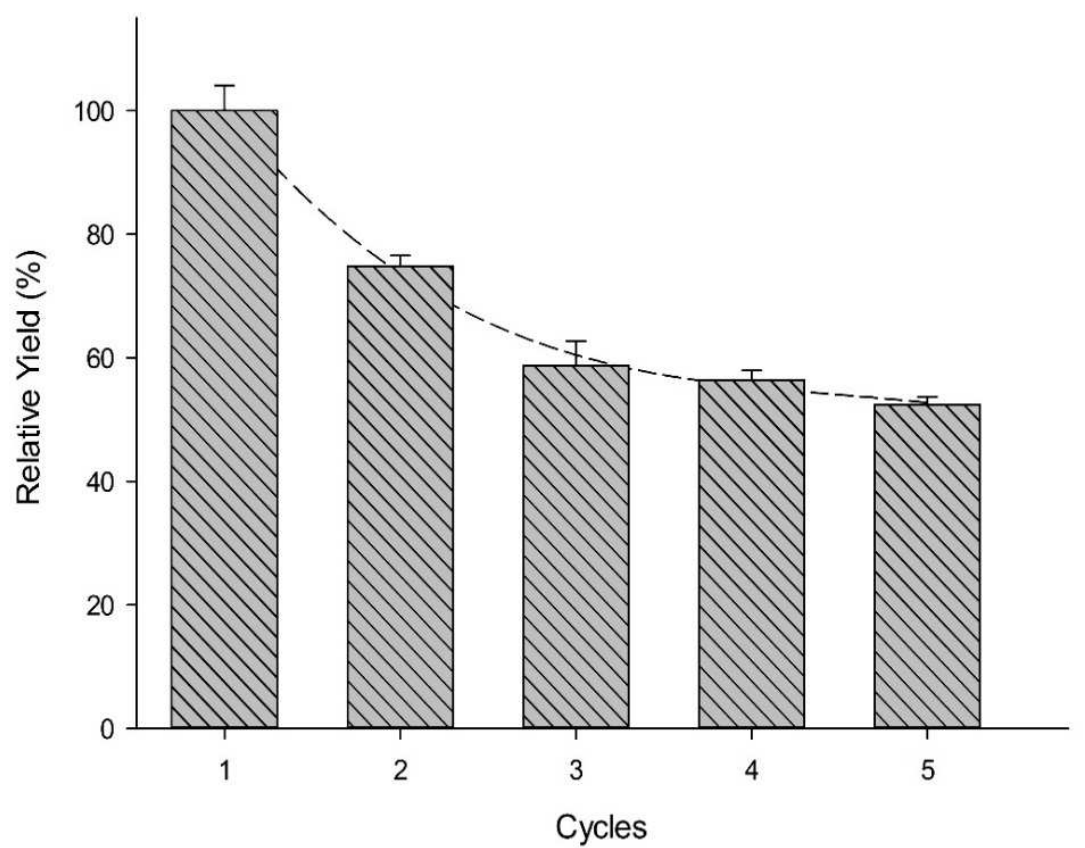

2 Figure 4. Relative yield (considering first reaction yield as 100\%) of 1-pulse ethanolysis 3 reactions. Methanolysis reaction is not shown due to the low yield achieved.

4 


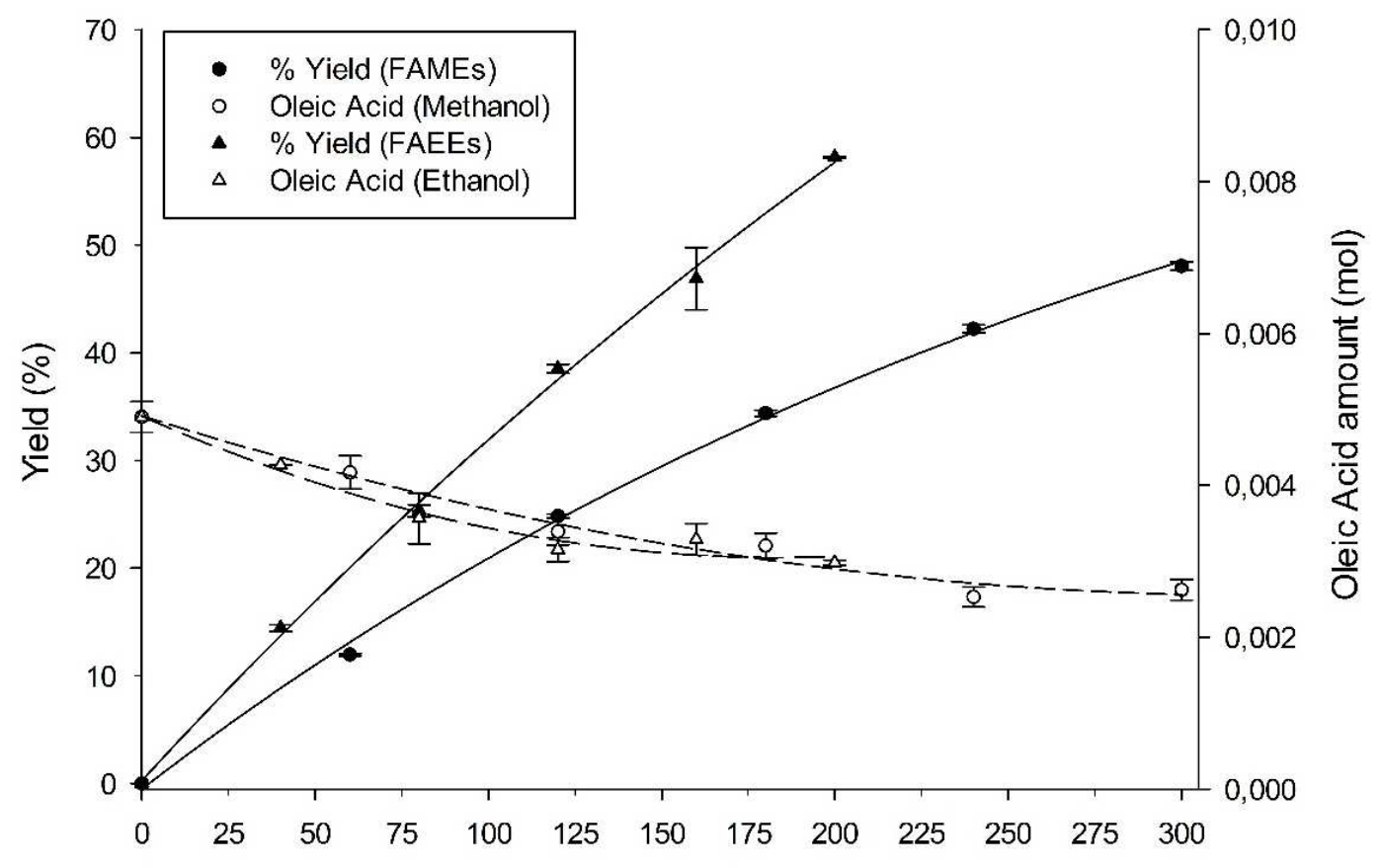

4

Time (min)

5

6 Figure 5. Time evolution of FAMEs, FAEEs yield and oleic acid of 5-pulse transesterification 7 reaction using methanol and ethanol. First five points correspond to five pulses (reaction 8 conditions: $8 \mathrm{~g}$ of alperujo oil, $1: 2$ alcohol to oil molar, $30^{\circ} \mathrm{C}$ and $350 \mathrm{rpm}$ ).

9 


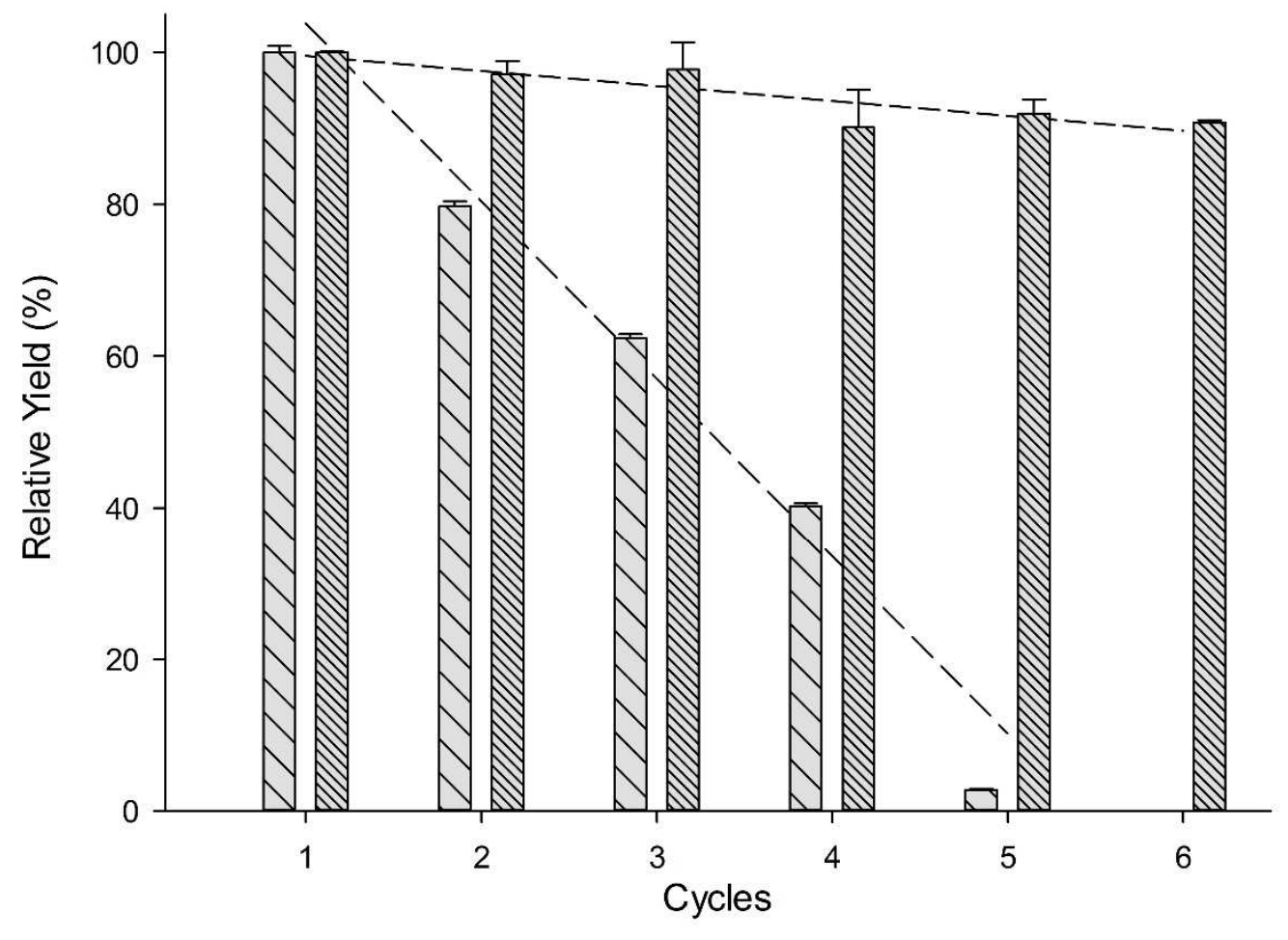

$\square \backslash$ methanol 5-pulse stability reactions MIV ethanol 5-pulse stability reactions

1

2

3 Figure 6. Relative yield (considering first reaction yield as 100\%) of 5-pulse methanolysis and 4 ethanolysis reactions.

5

6 


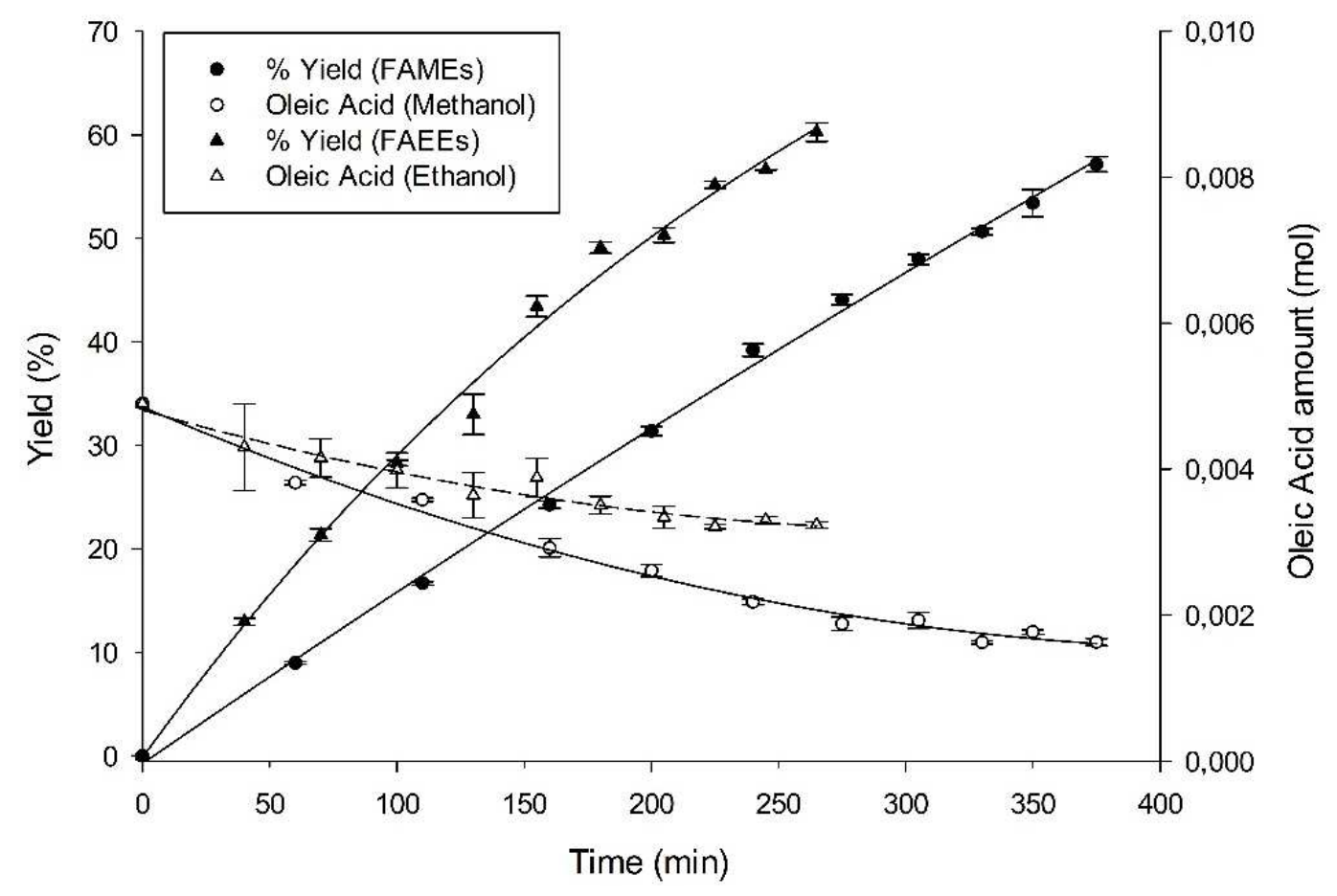

1

2

3 Figure 7. Time evolution of FAMEs, FAEEs yield and oleic acid of 10-pulse transesterification 4 reaction using methanol and ethanol. The first 10 points correspond to the 10 pulses (reaction 5 conditions: $8 \mathrm{~g}$ of alperujo oil, $1: 2$ alcohol to oil molar, $30^{\circ} \mathrm{C}$ and $350 \mathrm{rpm}$ ). 


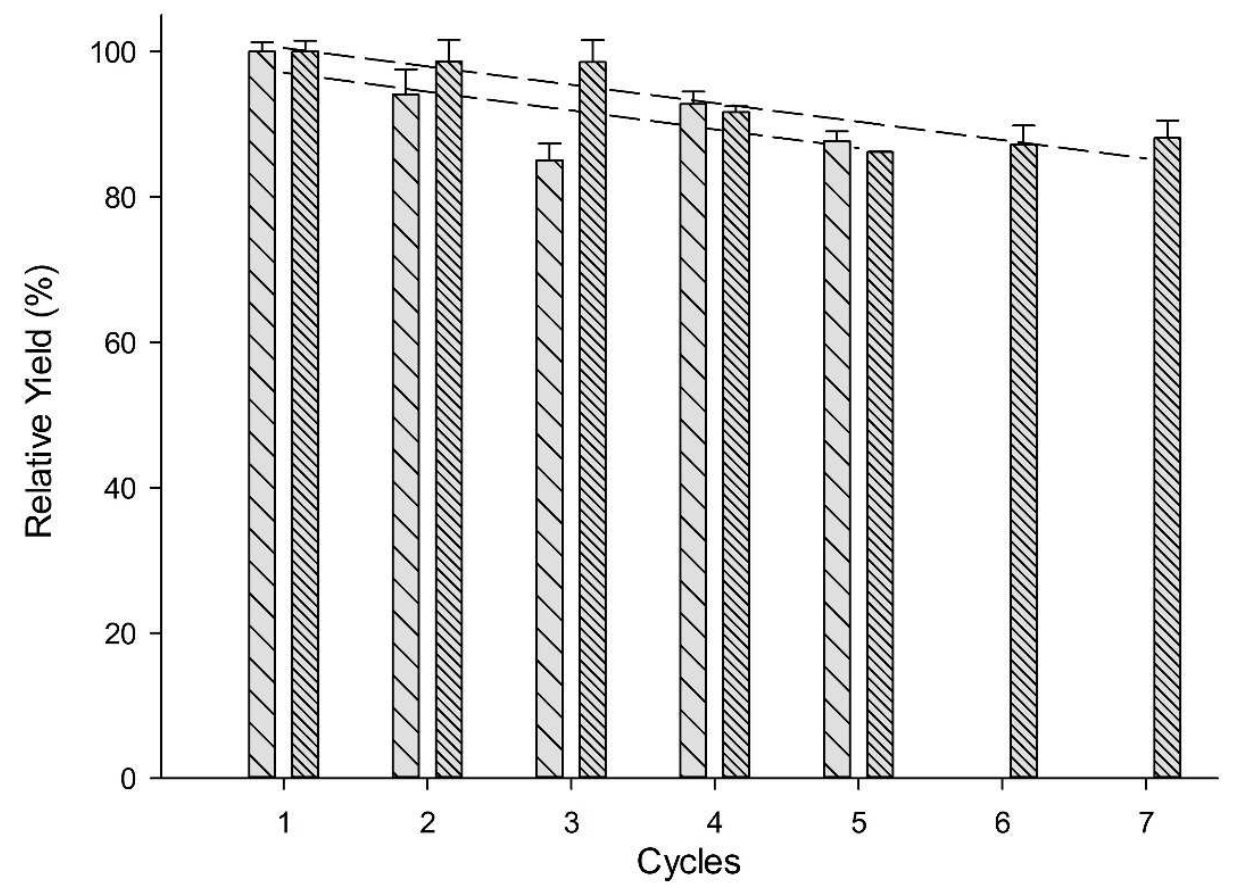

$\square \square$ methanol 10-pulse stability reactions MIV ethanol 10-pulse stability reactions

3 Figure 8. Relative yield (considering first reaction yield as $100 \%$ ) of 10-pulse methanolysis and 4 ethanolysis reactions.

5 
2

3 Table 1. Productivity values of biodiesel synthesis reactions by stepwise addition along the stability tests

\begin{tabular}{ll}
\hline Reaction & Productivity $(\mu \mathrm{mol}$ biodiesel/min) \\
\hline 5-pulse methanolysis & 3.91 \\
5-pulse ethanolysis & 7.17 \\
10-pulse methanolysis & 3.82 \\
10-pulse ethanolysis & 5.55 \\
\hline
\end{tabular}

4

5

6

7

8 